\title{
(Nueva) Arquitectura residencial para la (nueva) clase media de la costa norte peruana. Siglo xxI
}

\author{
Israel Romero Alamo \\ Universidad César Vallejo \\ Recibido: 30 de junio del 2018 / Aprobado: 2 de agosto del 2018 \\ doi: 10.26439/limaq2019.n005.4532
}

La arquitectura de la costa norte del Perú de los últimos años (siglo XxI), en específico la tipología residencial, viene formando una expresión arquitectónica de identidad en la que se manifiesta la idiosincrasia del proyectista (arquitecto) y su formación, así como la de sus formadores. Ella está basada en una clara postura posmoderna formalista, pero de intenciones y discursos modernos, que genera un lenguaje unificado y propio en un sector del país de facciones abiertamente limeño-dependientes. Pudo verse en los casos estudiados que se da la supremacía formal basada en una arquitectura visual y preocupada por la expresión arquitectónica y el predominio del significante, pero con un fuerte significado oculto de carácter económico y social.

clase media, posmodernidad, vivienda, costa peruana

(New) Residential architecture for the (new) middle class

from the Peruvian north coast in the 21st century

In the past years (21st century), the Peruvian north coast architecture, particularly the residential one, has been establishing an architectural expression of identity showing the idiosyncrasy of the designer (architect), his/her education and the education of his/her educators. It is based on a clearly postmodern stance, which is conventional but has modern intentions and discourses, and generates an own unified language in an area of the country openly reliant on Lima. Studied cases showed that there is a formal supremacy based on a purely visual architecture, concerned on the architectural expression and the predominance of the signifier, but with a strong hidden economic and social meaning.

middle class, postmodernity, dwelling, Peruvian coast 


\section{INTRODUCCIÓN}

La presente investigación analiza la arquitectura de una sociedad determinada en un espacio geográfico (la clase media de la costa norte del Perú) para encontrar un lenguaje arquitectónico particular que establezca indicios de identidad y singularidad frente a escenarios nacionales divergentes. Este lenguaje —expresado en la vivienda - tiene su origen no solo en la formación, sino también en los aspectos culturales, sociales y económicos de una sociedad que se inserta lentamente en la experiencia profesional (la arquitectura), pero muy rápido en un nivel adquisitivo predominante (la clase media peruana del siglo XXI).

Hablar de posmodernidad y arquitectura en el Perú nos lleva casi de manera forzosa a pisar terrenos de lo que se entiende como identidad, lo que, a su vez, engloba situaciones que ponen en tela de juicio la concepción totalitaria de “arquitectura peruana”. Por lo general, se pretende concentrar la peruanidad en una única tipología edilicia o estilo arquitectónico universal aplicable a cualquier contexto, realidad o situación geográfica o cultural del país, los que de por sí son distantes. Es entendible, desde este punto de vista, señalar las observaciones de dicho postulado.

Para desterrar esta idea históricamente predominante, es vital encontrar las distintas formas de expresión arquitectónica según las diversas situaciones geográficas y culturales del país. Esto representaría los primeros esbozos de la erradicación de la posición colonizadora, que pretende situar todas las manifestaciones nacionales en un reducto (limeño) centralizado al cual se le anexan, por fuerza más que por razón, otras expresiones culturales.

La evaluación de la costa norte, por sus antecedentes históricos, resulta de crucial importancia sobre todo para ver el grado de (in)dependencia del yugo centralista peruano/limeño del que han estado influenciados; asimismo, por el sostenido crecimiento económico de los últimos años y por representar uno de los sectores geográficos con mayor aumento de población profesional en arquitectura: según estadísticas del Colegio de Arquitectos del Perú (https://www.cap.org.pe), en los últimos diez años, departamentos como Piura, Lambayeque, La Libertad y Áncash duplicaron o triplicaron la cantidad de agremiados. Esta realidad es una constante que parece extenderse a lo largo del país. 
Estas características pueden verse específicamente en la participación del arquitecto en la tipología arquitectónica de mayor "necesidad" y expresión individual de crecimiento económico, y de libertad proyectual: la vivienda unifamiliar.

\section{ANTECEDENTES}

La arquitectura de la costa norte peruana tiene, en palabras de García Bryce (1962), una evolución orientada al quehacer limeño, por lo que considera dentro de su ejercicio, casi de forma evidente, a la guía capitalina, a diferencia de las ciudades de la sierra o del sur peruano. Esto es consecuencia del colonialismo y la persecución del modelo limeño en ámbitos culturales y socioeconómicos, que a su vez resulta en una trasposición del eurocentrismo (Quijano, 2014, p. 780).

Contextualizando la época de estudio —el siglo xxI (2000-2018)—, se entiende que la etapa formativa de la mayoría de los arquitectos que ejecutan hoy en día los edificios residenciales tuvo lugar desde la década de los noventa hasta mediados del 2000. En el contexto del norte peruano, en ese periodo, existía un predominio de la escuela limeña con orientación posmoderna porque hasta entonces era el principal lugar de formación. Además, aquella era la tendencia arquitectónica de la época. Hubo dos factores sobresalientes para esto: la influencia externa y la influencia interna.

\section{INFLUENCIA EXTERNA}

La influencia externa viene, en principio, por una transposición cultural común en la arquitectura: la occidentalización del producto arquitectónico. Esta se ha dado a lo largo de la historia. El contexto del objeto de estudio puntualiza algunos aspectos. A fines del siglo xx fue predominante la imagen del arquitecto estrella. Un arquitecto en el que impere su imagen o la de su obra (como ícono) resultaba de vital importancia para su ejercicio proyectual (Massad, 2015). Así, la obra terminaba convirtiéndose en una marca del apellido del arquitecto o de la oficina en cuestión; y aunque esta haya sido una característica común a lo largo de los últimos siglos, en las últimas décadas se ha dado una relativización notoria al respecto. 
Esa tendencia se expresaba en el énfasis que el proyectista le ponía al aspecto formal y visual del objeto, a la imagen, para que, en esta expresión arquitectónica o piel, quedara grabada la autoría del arquitecto.

Como antecedente de esto, existen los referentes del primer mundo alrededor de la década del setenta. Un ejemplo notable son los Five Architects, una neovanguardia tardomoderna que cuestionaba la modernidad de mediados de siglo Xx y su contraparte posmoderna de inicios de la segunda mitad del siglo pasado. En su arquitectura existen búsquedas formalistas a favor de una "arquitectura autónoma y alejada del funcionalismo reduccionista" (Frampton, 2014, p. 315). Ciertamente, se consiguieron logros categóricos y aportes teóricos coherentes, sobre todo en las obras de Eisenman o Hejduk.

Las obras de estos arquitectos se presentan como una marca proyectual de estrategias compositivas con base en criterios de organización de formas platónicas y colores básicos —a manera de una revisión del movimiento moderno lecorbusiano e incluso del neoplasticismo-. Esto se expresa en la identificación tridimensional del plano y la línea y su independización formal, en la explosión del volumen y en el movimiento y alteración de la convención compositiva tradicional, aunque también en la del movimiento moderno.

La presencia de una marca dentro de obras de características bastante cercanas a la imagen del proyectista dio pase al posterior término starchitect. En muchos de los casos, más que arquitectos serían estrellas que demostraban una supuesta superioridad proyectual y éxito comercial, lo cual los colocaba en la palestra mundial. Esta actitud fue adoptada de forma indirecta en el escenario nacional y, casi como consecuencia, el producto arquitectónico adquiría la misma connotación formalista y orientada al espectáculo. 


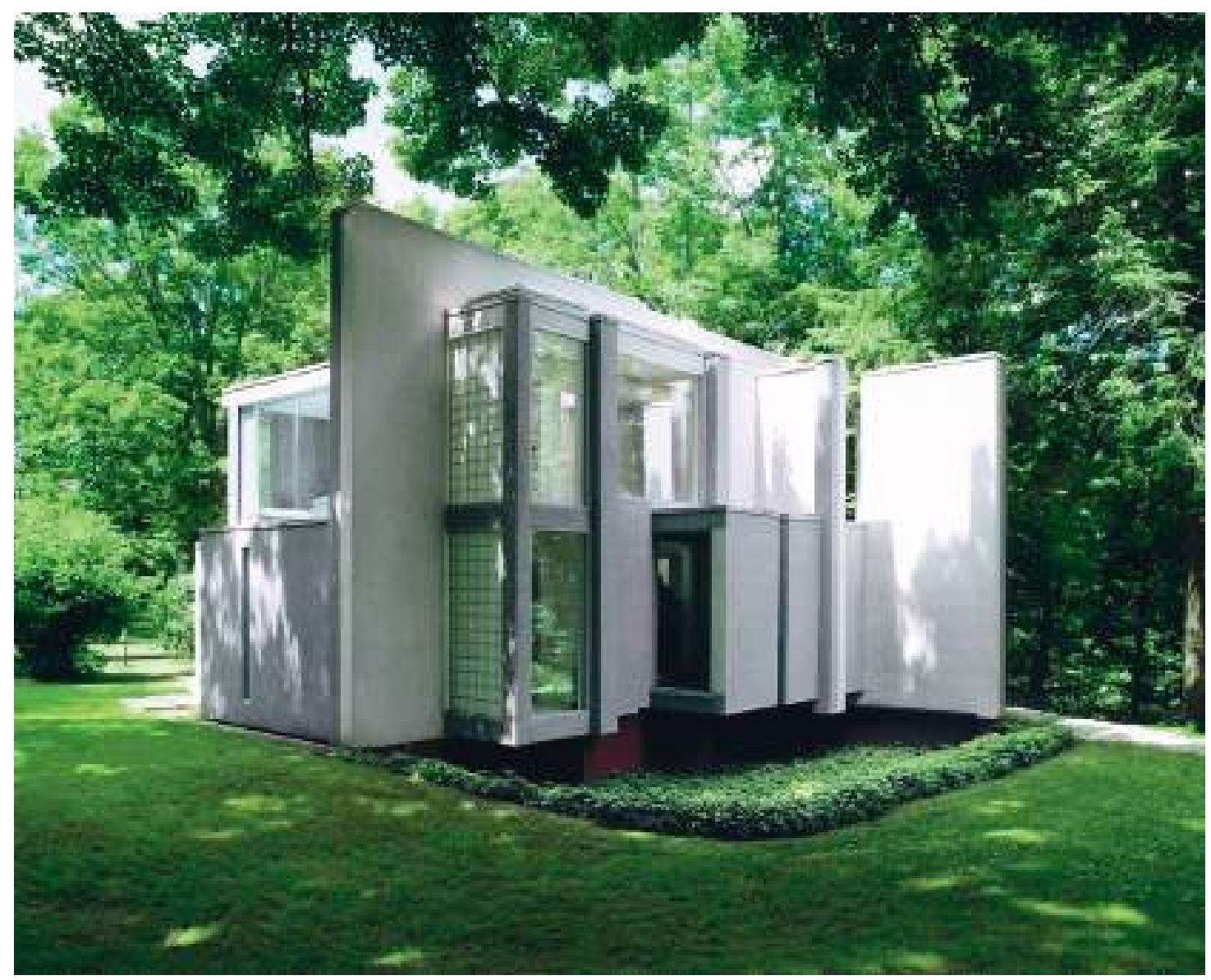

Figura 1. House VI, diseñada por Peter Eisenman

Fuente: Eisenman Architects, s. f. 


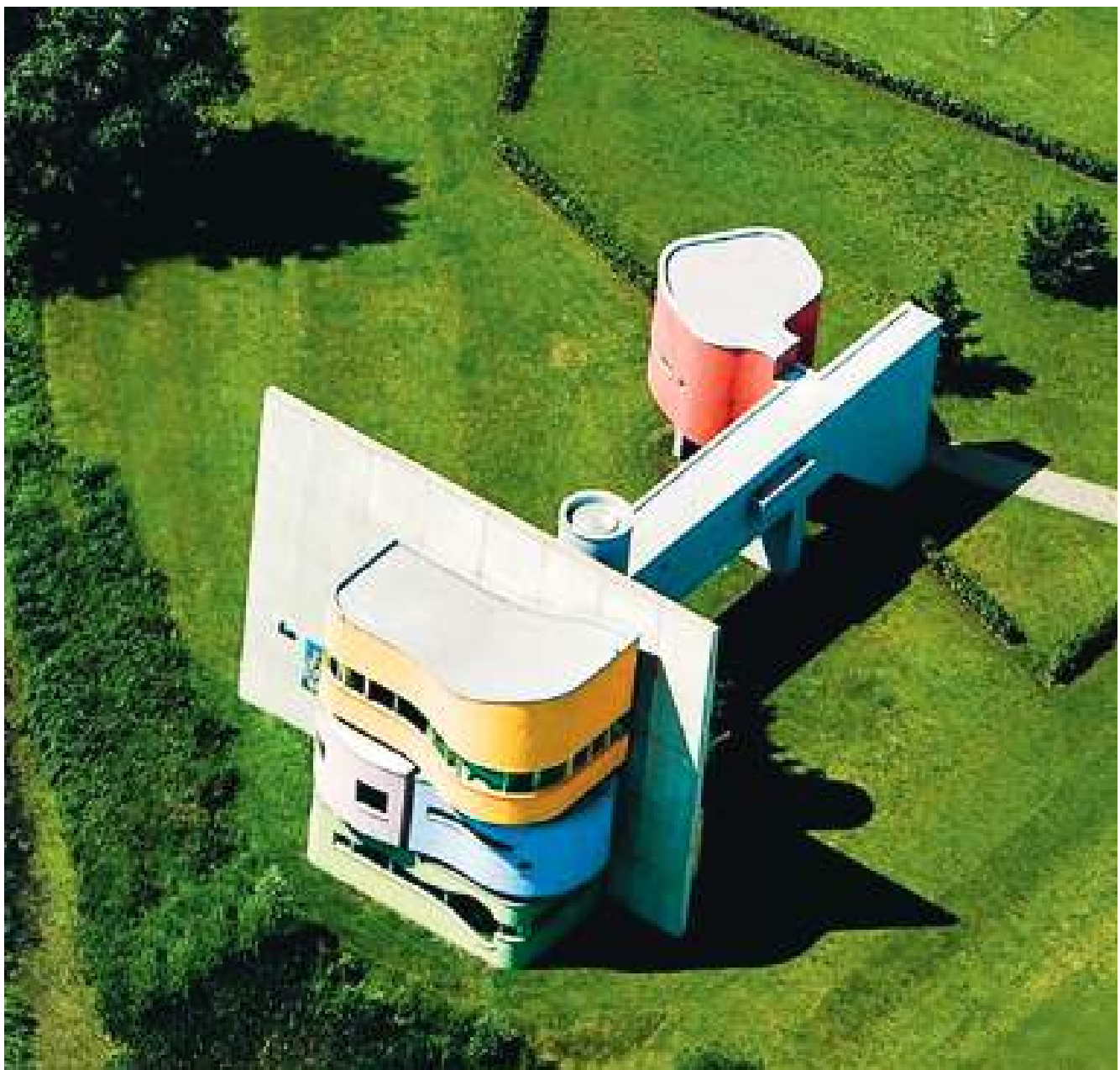

Figura 2. Wall House, diseñada por John Hejduk

Fuente: Sveiven, 2012 


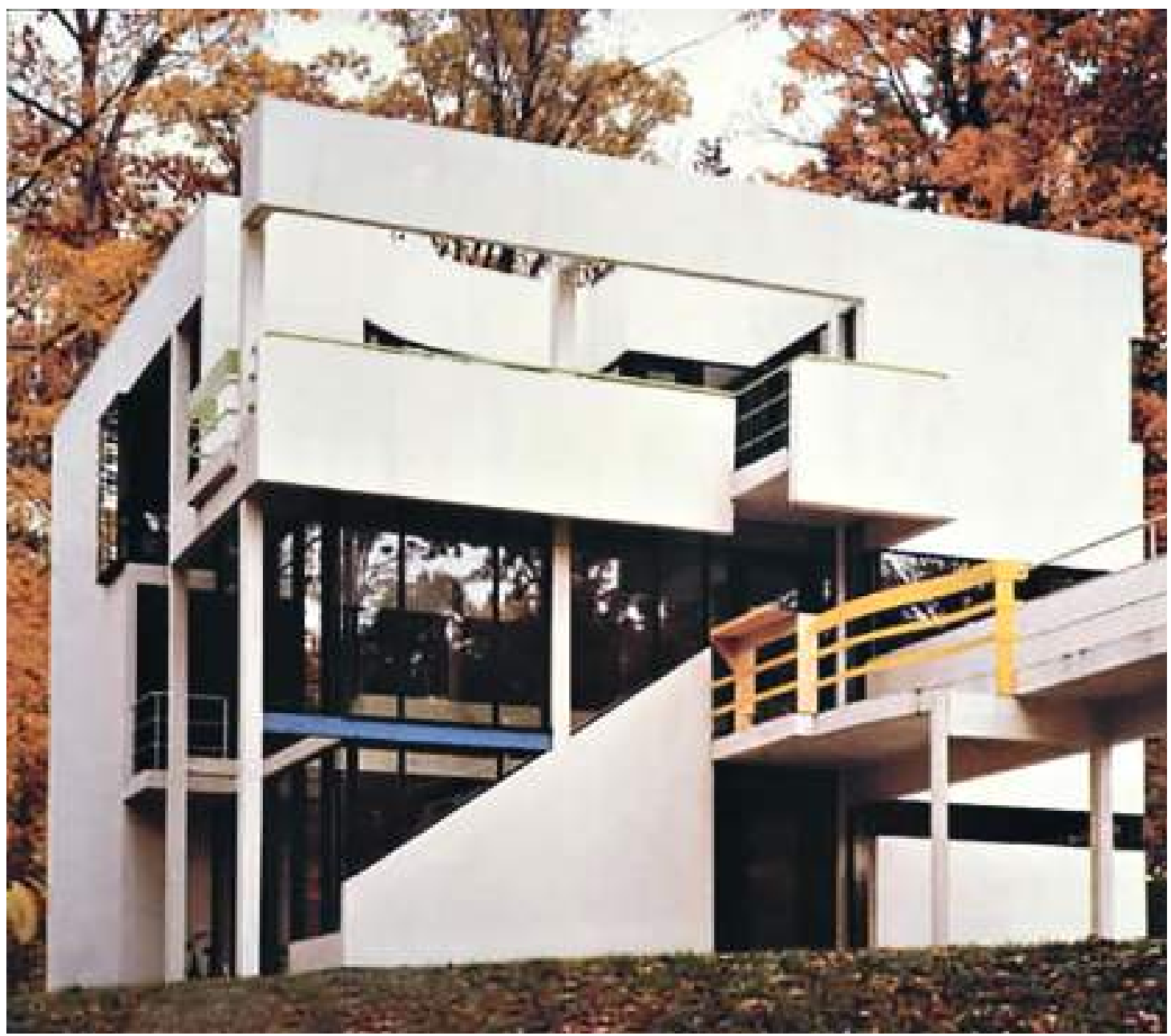

Figura 3. Hanselmann House, diseñada por el arquitecto Michael Graves

Fuente: Michael Graves. Architecture \& Design, s. f. 


\section{Influencia interna}

Una de las principales influencias internas se ha dado por la presencia limeña. Esto se ve reflejado en una de las escuelas que, en la actualidad, tiene un legado sobresaliente: la de Juvenal Baracco en la Universidad Ricardo Palma. Se le considera de gran influencia en el desarrollo arquitectónico (Ludeña, 1989, p. 89) no solo en Lima, sino también en el resto de ciudades del país —entre ellas, las del norte-, por una transmisión directa entre profesores y estudiantes.

Siendo la corriente posmoderna la predominante en la época, se optó por la utilización de teorías del proceso de diseño que justificaban el objeto final. Por ejemplo, el concepto y la metáfora eran cuestiones de suma importancia dentro del quehacer proyectual. Ambas se insertan en lo que Jencks reconoce como una apropiación del objeto moderno a manos de un pensamiento más "creativo", a partir de la libre interpretación de los signos del proyecto o edificio (1981, p. 40). Estos episodios consiguen una supuesta mayor riqueza para el objeto final, pues no solo tienen una lectura racional y funcional, sino también una imagen connotativa, compuesta por diversas subjetividades.

Estas soluciones terminaron expresándose en desarrollos básicamente formales (y luego espaciales) como imperativo de lo visual dentro del ejercicio proyectual. Por ello, a diferencia de décadas anteriores, existe en el ejercicio proyectual, incentivado desde la formación de la década del noventa, una preocupación prioritaria por la forma (y su trasfondo) que el arquitecto considera como fin casi supremo al momento de proyectar: el diseño debe tener un concepto. Para muchos proyectistas contemporáneos es necesario ver al significado otorgado por él mismo como acompañante congénito del significante.

Este aspecto, en contextos universitarios básicos, resulta positivo, puesto que desarrolla e incentiva el trabajo creativo del arquitecto en formación. No obstante, en situaciones posteriores, como las del ejercicio profesional, puede llegar a entenderse como caminos (o ejercicios) que seguir al pie de la letra, casi forzados o automatizados. En muchos casos se ha visto que un proyecto tiene una supuesta menor valía si carece de una conceptualización. Por ejemplo, en concursos tanto académicos como profesionales, uno de 
los requisitos de primer orden resulta ser el concepto o idea base detrás del proyecto. La carencia de este le resta sustento, como si necesitara de un discurso para valerse.

Esto marcaba la enseñanza limeña durante las décadas de los noventa y la primera del siglo xxi. Ello tuvo repercusión en los estudiantes que eran de otras ciudades y estudiaron en Lima, o los docentes que de Lima iban a enseñar en otras ciudades, o en quienes entendían y asimilaban el espíritu de la época.

Escuelas con una formación de estas características en el norte del Perú son, por ejemplo, las de la Universidad Privada Antenor Orrego, la Universidad César Vallejo o la Universidad Particular de Chiclayo. Sin embargo, esto no es exclusivo de dichas casas de estudio ni limita la inclusión de otros espacios universitarios u otros lugares del país.

Como se mencionaba, entre la última década del siglo xx y la primera del XxI, se dio pase a una arquitectura formalista. Como estrategias de proyección arquitectónica, fueron fundamentales los principios y las características de composición, de asociación volumétrica y también los principios de organización espacial, pues eran los que aterrizaban de mejor forma en la exigencia formalista de entonces.

Teniendo en cuenta el contexto de la época (que incluye tanto la influencia externa como interna), puede verse que parte de las enseñanzas locales tienen también su origen en algunas de las soluciones arquitectónicas formalistas de Five Architects, pues se las entendía como soluciones y estrategias proyectuales idóneas para los fines formalistas que se pretendían. No obstante, muchas de estas soluciones fueron comprendidas solo de manera superficial y visual, como justificación de intereses expresivos, conceptuales y metafóricos; en definitiva, como búsquedas intencionadas para el producto final.

Como acotación, hay que resaltar que esta mala interpretación de la teoría y la banalización de la formación (arquitectónica) fue generada por un producto, también de la época, no menos importante: la privatización (y comercialización) de la educación (superior) a manos de la dictadura fujimorista de aquellos años, lo que desembocó en una mala calidad de la formación de los arquitectos. 
Combinadas estas situaciones, se tiene como producto, en el contexto nacional, una arquitectura "de la imagen" de la mano de una formación banalizada que incentiva el lenguaje arquitectónico como demostración de creatividad proyectual y de identidad proyectista-obra, así como un predominio sin justificación de la imagen del proyectista y del sello que debe adquirir la obra: una banalización generalizada del proyecto arquitectónico. Este producto se aleja sustancialmente tanto de los trabajos racionalistas (de entraña en el movimiento moderno, el cual se dejó de lado durante la época) como de los convencionalismos de la arquitectura tradicional y contextualista — que antes se mostraban como únicos y (a veces) antagónicos — para dar pase a un nuevo tipo de producto.

En la tabla 1, se aprecian los criterios compositivos que se deben tener en cuenta en el diseño arquitectónico básico. Estos se muestran como requisitos elementales para el entendimiento del espacio y la forma y la posterior "conversión" en arquitectura.

\section{LA CLASE MEDIA EMERGENTE}

Existe un tercer factor ajeno a los profesionales y procesos formativos expuestos: el socioeconómico y cultural. El contexto nacional de las últimas décadas aumentó el nivel adquisitivo de la población, por lo que se desarrolló una clase media emergente (como en Lima) que, a pesar de contar con nuevas adquisiciones o mejoras sociales y económicas, mantiene culturalmente ciertos rasgos tradicionales, como las costumbres o los gustos, pero que opta por lo que ella entiende por modernización (Matos Mar, 2012, p. 44).

Como demostración de la mejora social y económica, se hace presente la adquisición de productos nuevos: vehículos, vestimenta o vivienda. La expresión de la vivienda se ve resaltada por la imitación y la convocatoria masiva de diversos motivos para expresar un natural anhelo de modernidad o de querer ser moderno (Dreifuss, 2013, p. 97). En esta suma de intenciones es que resaltan algunas características notables de la sociedad peruana actual, como la necesidad de expresión y de demostración de los logros y lo obtenido, o el exhibicionismo sin mayor mesura. 
Tabla 1

Forma-espacio

\begin{tabular}{|c|c|c|c|c|}
\hline \multicolumn{5}{|c|}{ FORMA - ESPACIO } \\
\hline \multirow{3}{*}{ ELEMENTOS FORMALES } & Puntos & & j & \\
\hline & Líneas & $\Rightarrow$ & 3) & \\
\hline & Planos & & & \\
\hline \multirow{2}{*}{ CARACTERÍSTICAS DE LA FORMA } & Regulares & [ & & \\
\hline & Irregulares & & 1000 & \\
\hline \multirow{2}{*}{ PRINCIPIOS DE COMPOSICIÓN } & Adición & $\square$ & & \\
\hline & Sustracción & & & \\
\hline \multirow{4}{*}{ CARACTERISTICAS DE LA COMPOSICIÓN } & Contacto & $\square$ & & \\
\hline & Penetración & 昰 & & \\
\hline & Articulación & $\mathrm{P}_{11}$ & $\Delta \Perp$ & \\
\hline & Yuxtaposición & $A x$ & & \\
\hline \multirow{3}{*}{ CARACTERISTICAS DE LA COMPOSICIÓN } & Compacta & 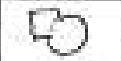 & $\widehat{\Lambda}$ & QI] \\
\hline & Semicompacta & $\square_{0}$ & $\Delta_{1}$ & ore \\
\hline & Dispersa & ${ }^{0} \Delta^{0}$ & $\square D \square$ & {$[\square \triangle D$} \\
\hline \multirow{4}{*}{ PRINCIPIOS DE ORGANIZACIÓN } & Proporción & & 1. & \\
\hline & Equilibrio & & & \\
\hline & Jerarquía & $\begin{array}{l}\text { ryan } \\
\text { ang }\end{array}$ & ${ }_{0}^{\circ}{ }_{11}^{\circ}$ & \\
\hline & Ritmo & 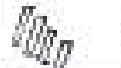 & केष्ठ & \\
\hline \multirow{3}{*}{ ESTRUCTURA COMPOSITIVA } & Simetría/asimetría & $\square$ & $\square_{\mathrm{O}} \mathrm{O}$ & $V_{i}$ \\
\hline & Ejes & & & \\
\hline & Geometría & $D A$ & & $\Delta$ \\
\hline
\end{tabular}

Separata académica de composición formal-espacial de la cátedra del docente Raúl Huaccha (Universidad Privada Antenor Orrego)

Fuente: Huaccha, 2012a 


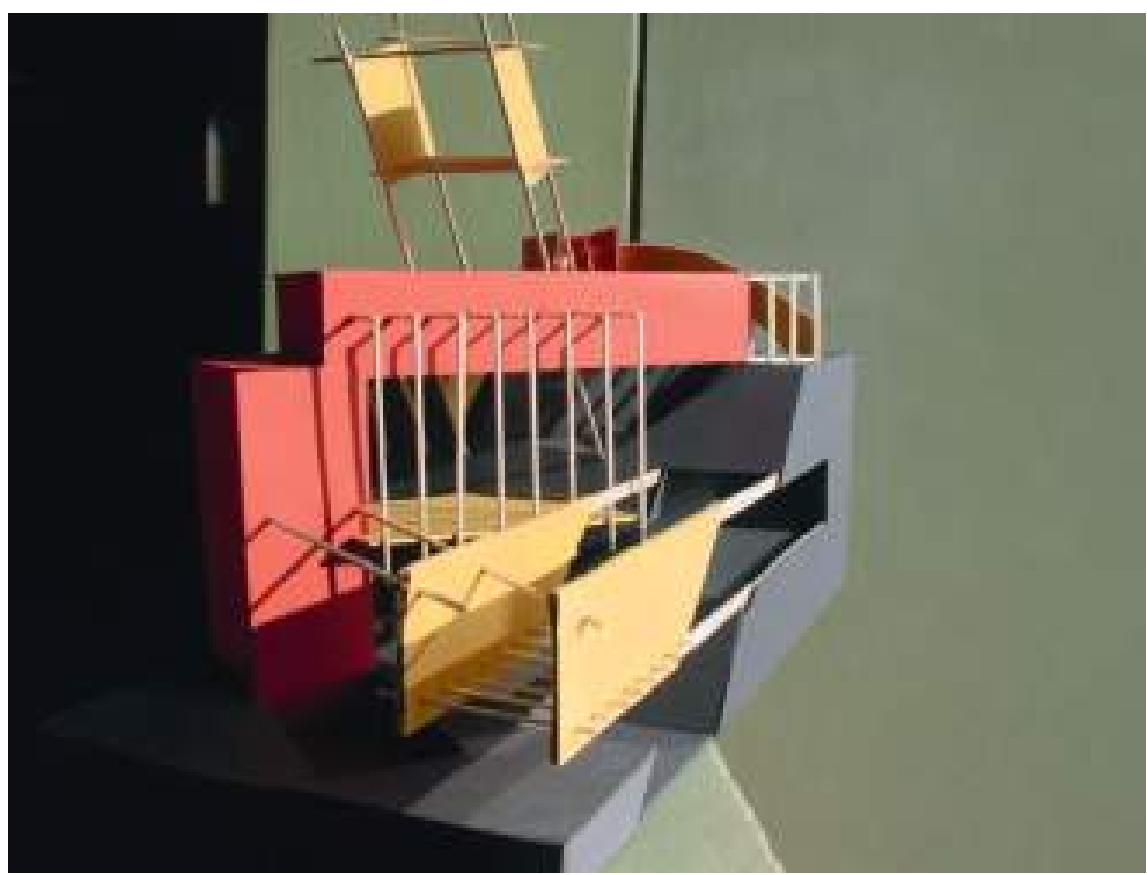

Figura 4. Fotografía de composición volumétrica elaborada en el año 2004 en el Taller de Proyectos, en la cátedra de Raúl Huaccha. Universidad Privada Antenor Orrego

Fuente: Huaccha, 2012b

Esta realidad no se da solo en el caso peruano; la bonanza económica de distintas sociedades ha dado pase a escenarios parecidos en distintos lugares del globo, en los que la arquitectura sirve para expresar el nuevo estado adquirido. Tal es el caso del fenómeno Mamani en Bolivia o la arquitectura de remesas en Centroamérica. 


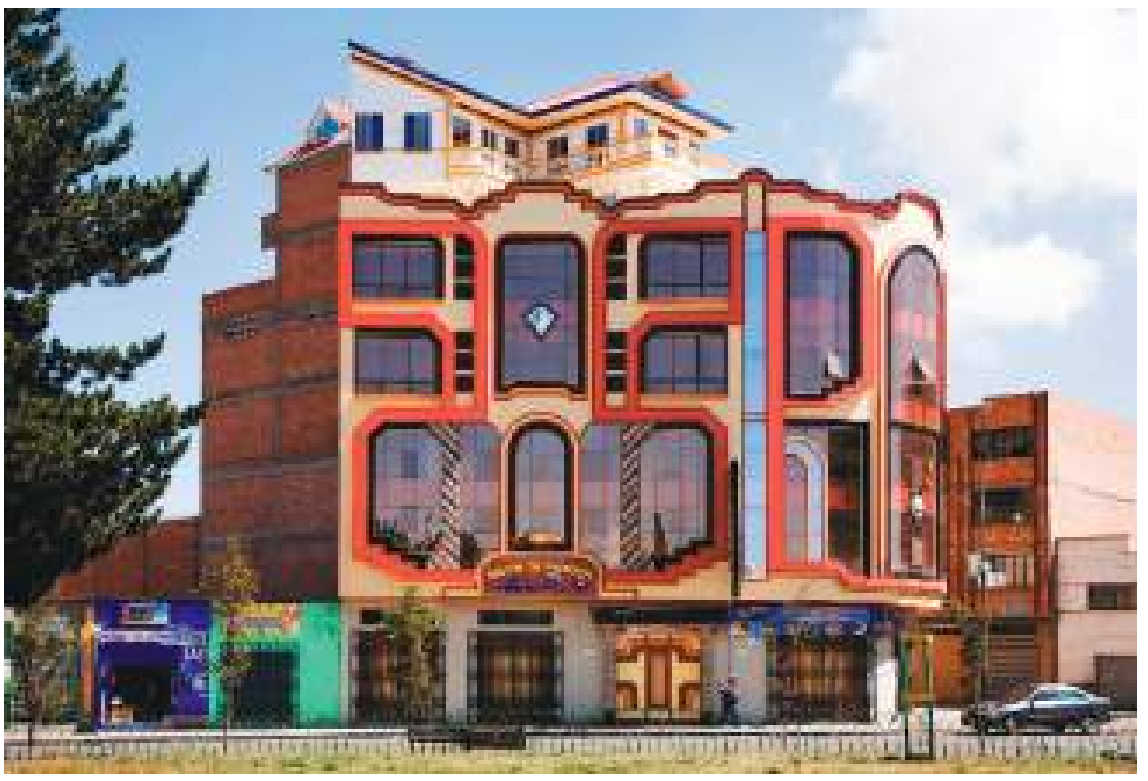

Figura 5. Arquitectura andina en Bolivia, diseñada por Freddy Mamani

Fuente: Valencia, 2017

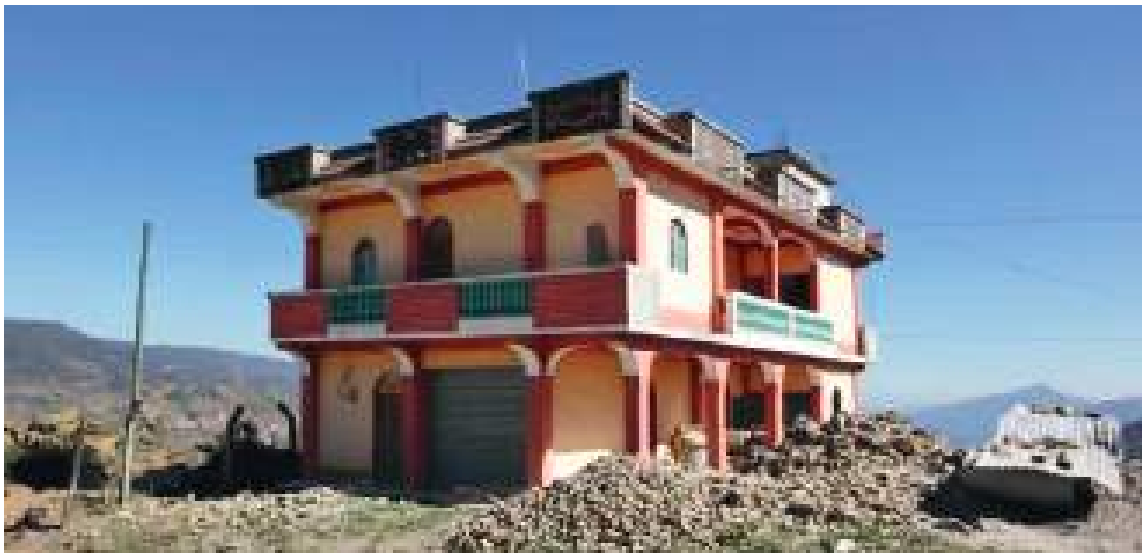

Figura 6. Arquitectura de remesas en El Salvador

Fuente: Iraheta, s. f. 
Si bien el predominio de lo propio y de la autoconstrucción determina un alto porcentaje de la imagen de las ciudades, también existe un creciente índice de inclusión de la labor proyectual profesional de arquitectos jóvenes (formados bajo las premisas y los factores indicados) que cuentan con características socioculturales y económicas también emergentes, afín a sus clientes y usuarios. Es decir, las adquisiciones y mejoras económicas van paralelas con la formación de profesionales dentro de las familias emergentes, quienes en muchos de los casos son los primeros miembros que obtienen dicho estatus.

En este caso, el ser profesional (arquitecto) no elimina los rasgos culturales de casa; por el contrario, los incluye en la labor proyectual durante la formación y el ejercicio profesional. El racionalismo - como factor cultural y proyectual - no tiene mucho espacio de acción en este grupo social. Por el contrario, resaltan de forma sobresaliente el exhibicionismo en los ámbitos sociocultural y académico-proyectual. Al momento del ejercicio proyectual es cuando lo asimilado en la academia se ve expresado en criterios compositivos cada vez más orientados a la expresión superficial o el barroquismo de la obra. Por un lado, se ve una transmisión indirecta de la arquitectura como objeto y marca, propio de lo aprendido en las aulas, del formalismo y el exhibicionismo del starchitect de fines de siglo xx e inicios de siglo XXI; y, por otro, la formación acrítica frente a las modas de turno, sumado a los aspectos sociales y culturales que naturalmente envuelven al proyectista. 


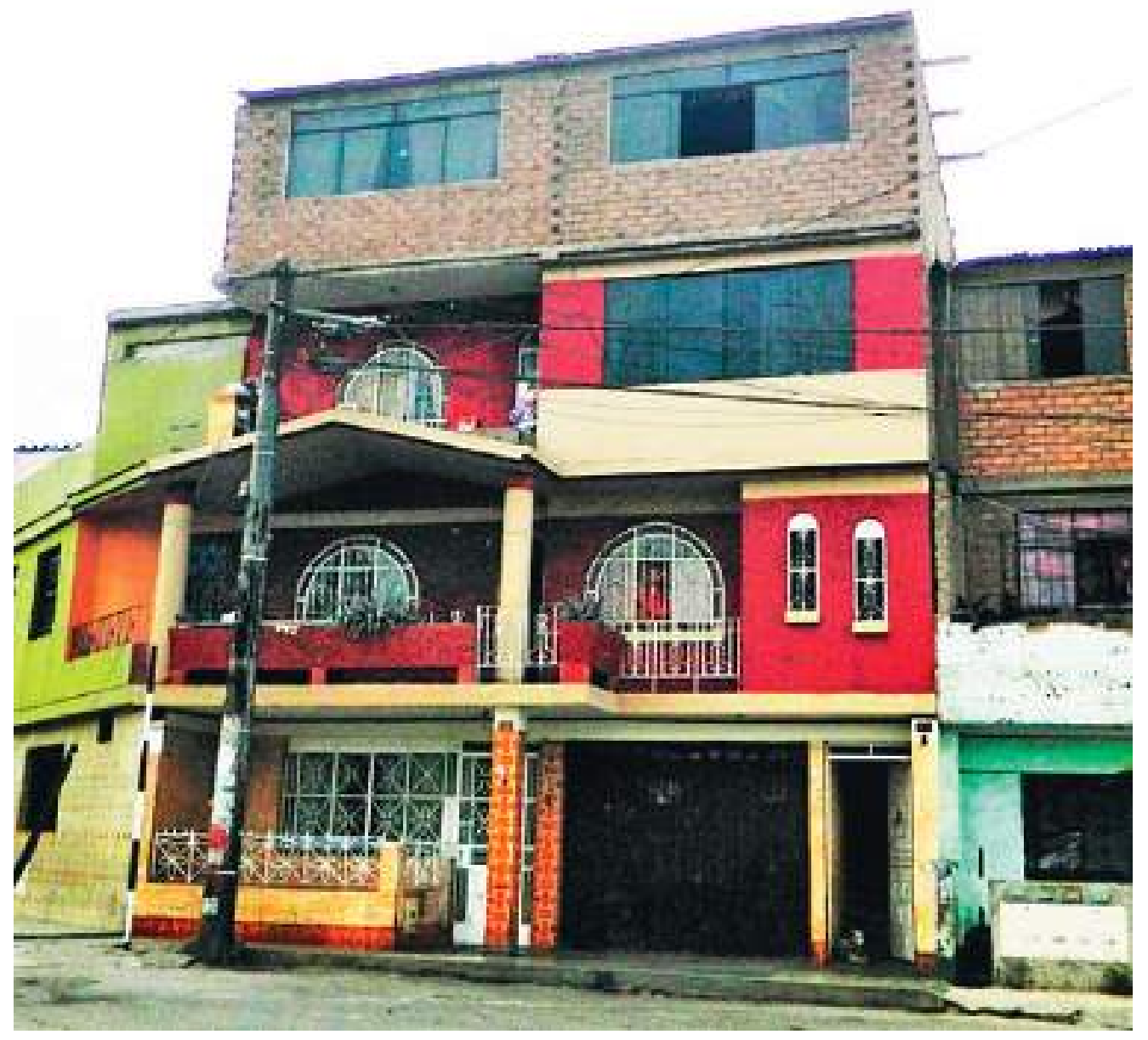

Figura 7. Tendencia barroca en viviendas populares urbanas (Lima Norte)

Fuente: Uglyperuvianhouses, 2018 


\section{RESULTADOS}

Se observa una arquitectura formalista tardomoderna (como influencia extranjera), recargada (como manifiesto del barroco cultural) y con justificaciones posproyecto que validan el objeto, sumadas a artilugios proyectuales basados en la expresión edilicia (influencia nacional).

En la situación urbana de los contextos locales, estos edificios no se muestran como en el ideal primermundista o en el de las aulas universitarias. Al volcarse en la realidad (norperuana), se presentan como un maquillaje tridimensional expuesto en lotes reducidos de uno o - en el mejor de los casos - dos frentes. La disposición austera del lote urbano, sumada al factor económico — este último casi siempre positivo, pues permite experimentos de varios tipos-, genera productos arquitectónicos con las características que se verán a continuación.

\section{Aplicación forzada de la teoría}

Existe una notoria intención de volcar el ejercicio (teoría del diseño y criterios de composición) solo en los frentes, como si fuera el único espacio permitido para hacer visible la capacidad proyectual y, por tanto, exhibirse.

En el frente se insertan los recursos tardomodernos (formales) - por ejemplo, la idea de ritmo, repetición, asociación de volúmenes, etcéterasin mayor consideración del limitado espacio de acción. Es frecuente el uso de elementos independientes interconectados (a lo que se le llama contacto, penetración o articulación) para finiquitar la organización del frente. También se hace presente la demarcación de vanos, la independencia del plano y la línea, y la disociación cromática y material acorde y según la separación de las formas.

En muchos casos, esta aplicación es el objetivo final de la obra (o sea, se diseña para la fachada) o el paso final para consumar la obra, lo que da lugar a edificios resultadistas en los que la fachada no es necesariamente producto del desarrollo interior del edificio, sino un proceso independiente (figuras 10 y 12). 


\section{Atracción por la "modernidad"}

Es recurrente ver en estas obras la utilización de materiales diversos vistos en revistas o proyectos de vanguardia, o de moda en los ámbitos nacional e internacional. La intención de incluirlos en la fachada no se encuentra en función de los requerimientos formales de los frentes; por el contrario, se basa en la necesidad de utilizarlos para demostrar que el edificio es "moderno".

Existe una fuerte tendencia a la aplicación de (imitaciones de) piedra, enchapes de diversos tipos — como porcelanato o cerámico-, muros cortina, concreto expuesto o madera, como expresión del dominio y conocimiento para dar diversas soluciones en los revestimientos. De esta forma, la obra se convierte en un contenedor de materiales entendidos como vanguardistas. Mientras se los utilice de mayor calidad o costo, puede inferirse que la obra (y el arquitecto) es superior en términos proyectuales (figuras 8,9 y 10 ).

\section{Barroquismo}

Se puede observar la inclusión, muchas veces desmedida, de formas, texturas, colores (discordantes) y demás recursos compositivos. Se manifiesta aquí un horror vacui inconsciente expresado en un natural "menos es aburrido". En este caso, existe una contradicción notoria, y es que la teoría proyectual utilizada por lo general apunta a un supuesto racionalismo proyectual (aunque con limitaciones, justificado en ciertas formas ortogonales o colores sobrios). Con todo, las obras tienden a concentrar varias adiciones de manera ostentosa que resultan conflictivas. Puede verse también la extensión sociocultural precedente en el proyectista, acompañada de la complicidad y el gusto del cliente/usuario, quien valida y apoya dichas soluciones (figuras 8, 9, 10 y 12 ).

\section{Esquizofrenia proyectual}

Como complemento de la aplicación forzada de la teoría —en la que se presenta una común disociación proyectual entre la planta y las elevaciones por ser estas las últimas en trabajarse, casi como un retoque para una 
función genérica-, existe también el desentendimiento de la obra frente al contexto. Aun cuando la situación urbana en la que se inserta es por demás bastante densa, consolidada y con líneas similares, el proyectista suele obviar lo que le rodea para ensimismar su obra en el terreno: omite alturas y retiros vecinos y se ciñe, en algunos casos, solo a lo estrictamente reglamentario.

Esto puede verse en la falta de armonía del perfil urbano con frentes discordantes y alturas poco resueltas. Además, es una constante que los frentes suelen ser bastante pensados y trabajados, pero los muros colindantes carecen de tratamiento, de modo que quedan a expensas del vecino, también en total complicidad con el propietario del edificio (figuras 9 y 11).

\section{Tergiversación del significado}

Se presenta la necesidad de utilizar formas más allá de la constitución edilicia originaria, por ejemplo, con la incorporación del drywall: la vivienda suele travestirse para incentivar una imagen particular de sí misma. El edificio se comporta más como un escaparate comercial que como una vivienda, pues altera su significado: la vivienda no parece vivienda a causa de las pretensiones proyectuales.

Existe también una aplicación (por lo general forzada) del concepto como mecanismo de justificación de la obra y que resulta incongruente con el resultado final, así como una falta de correspondencia entre significado y significante al otorgar al edificio una "razón de ser" de pretensión primermundista y al obviar los rasgos culturales tradicionales que contienen.

Es en esta característica donde pierde fuerza lo que Jencks mencionaba, en defensa de la arquitectura posmoderna, sobre el signo simbólico del objeto (1981, p. 54), pues el significado "convencional" del objeto se ve transgredido por ejercicios de índole moderna que lo que consiguen no es más que dificultar la lectura del edificio (figuras 10, 12 y 13). 


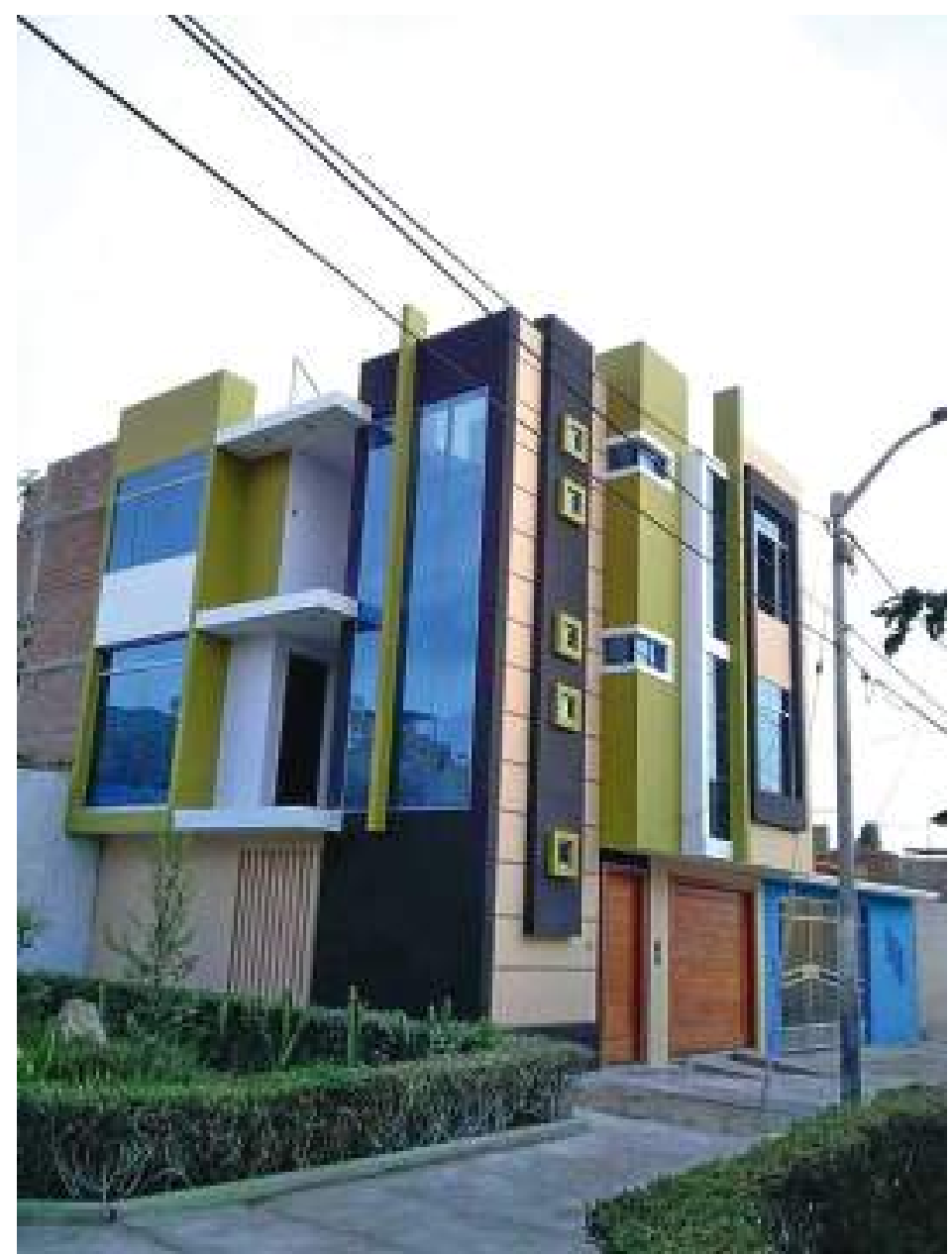

Figura 8. Caso 1 (Chimbote, 2012)

Fuente: archivo fotográfico de Richard Asto 


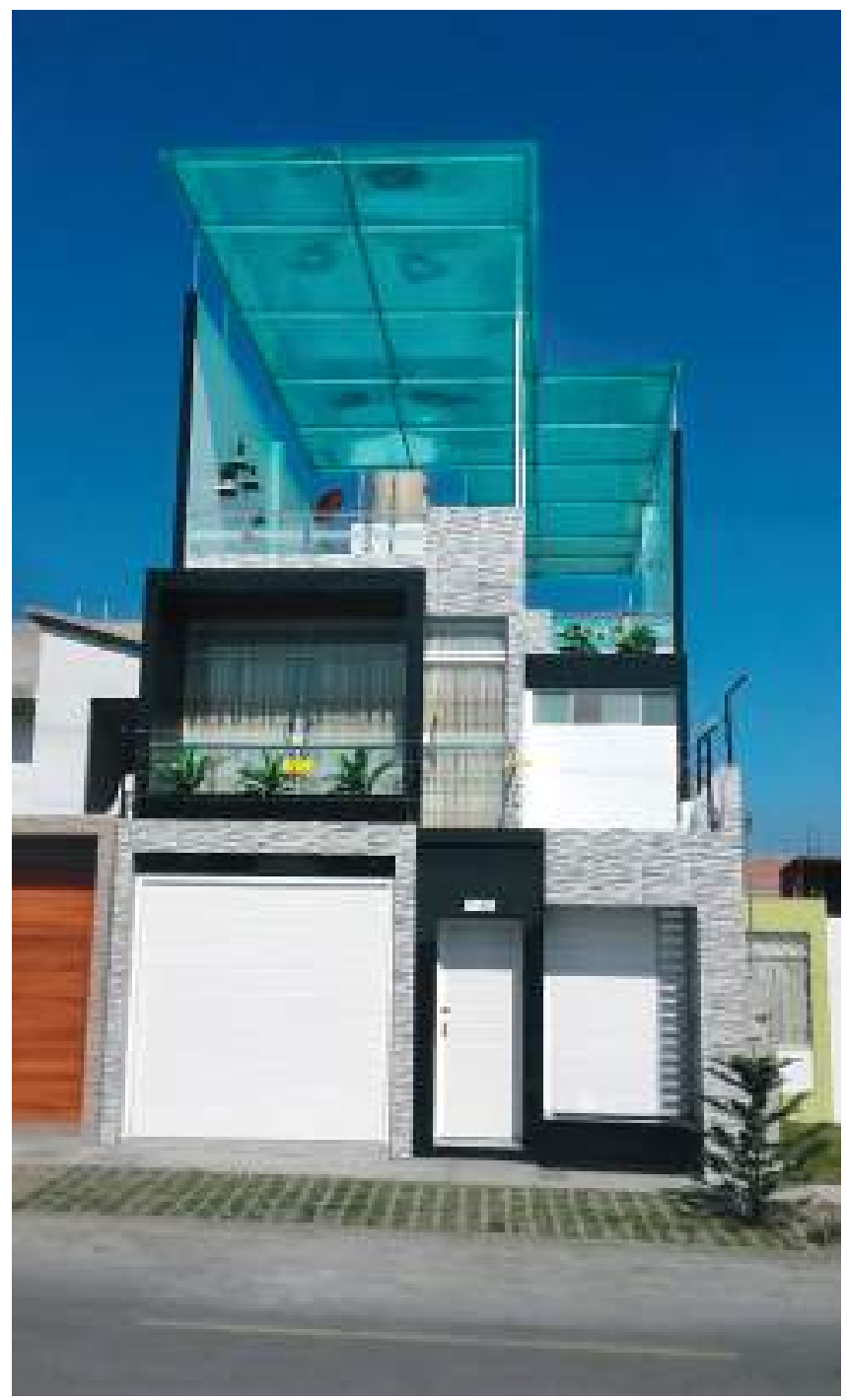

Figura 9. Caso 2 (Trujillo, 2017)

Fuente: fotografía del autor 


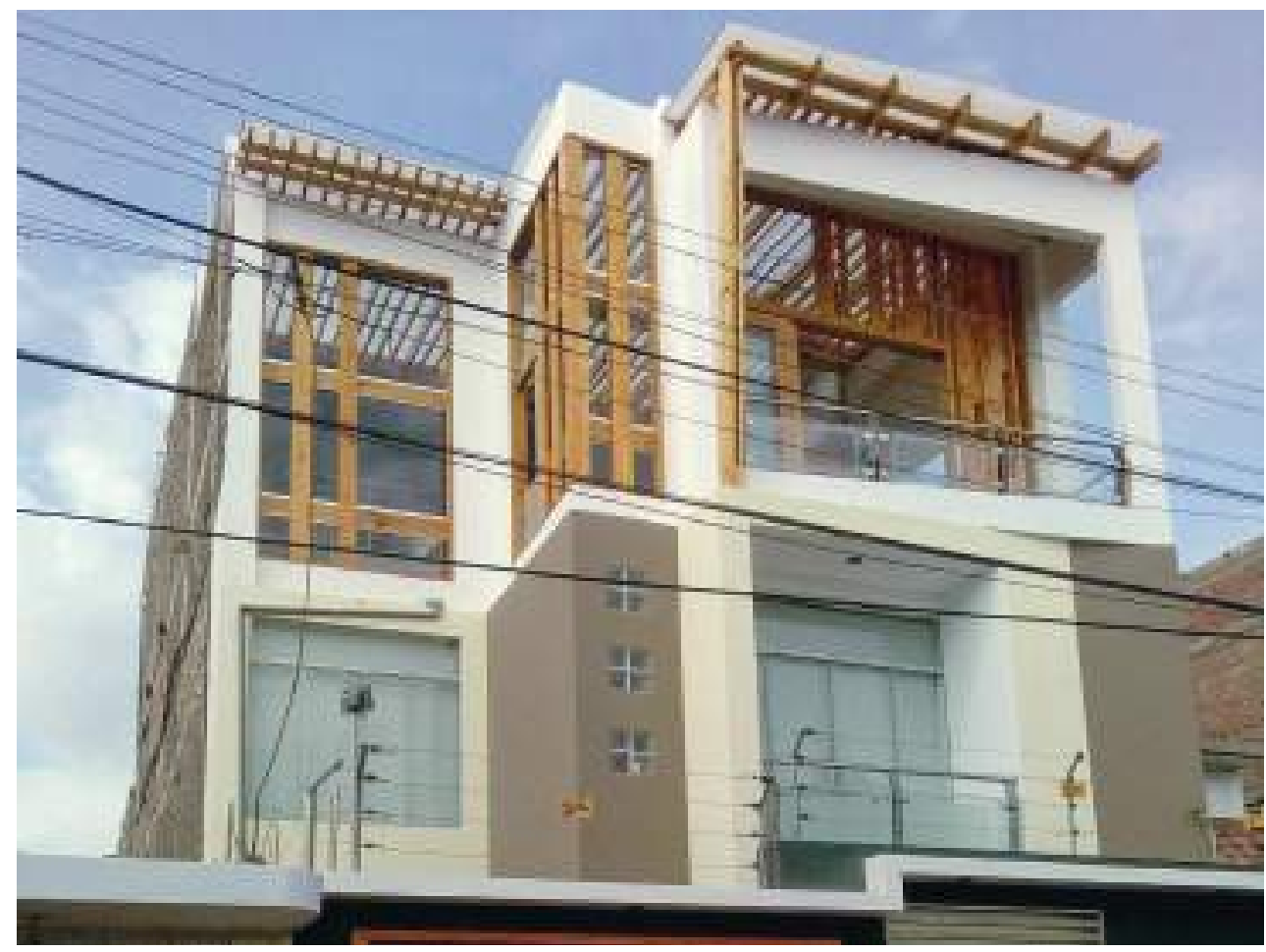

Figura 10. Caso 3 (Chimbote, 2010)

Fuente: fotografía del autor 


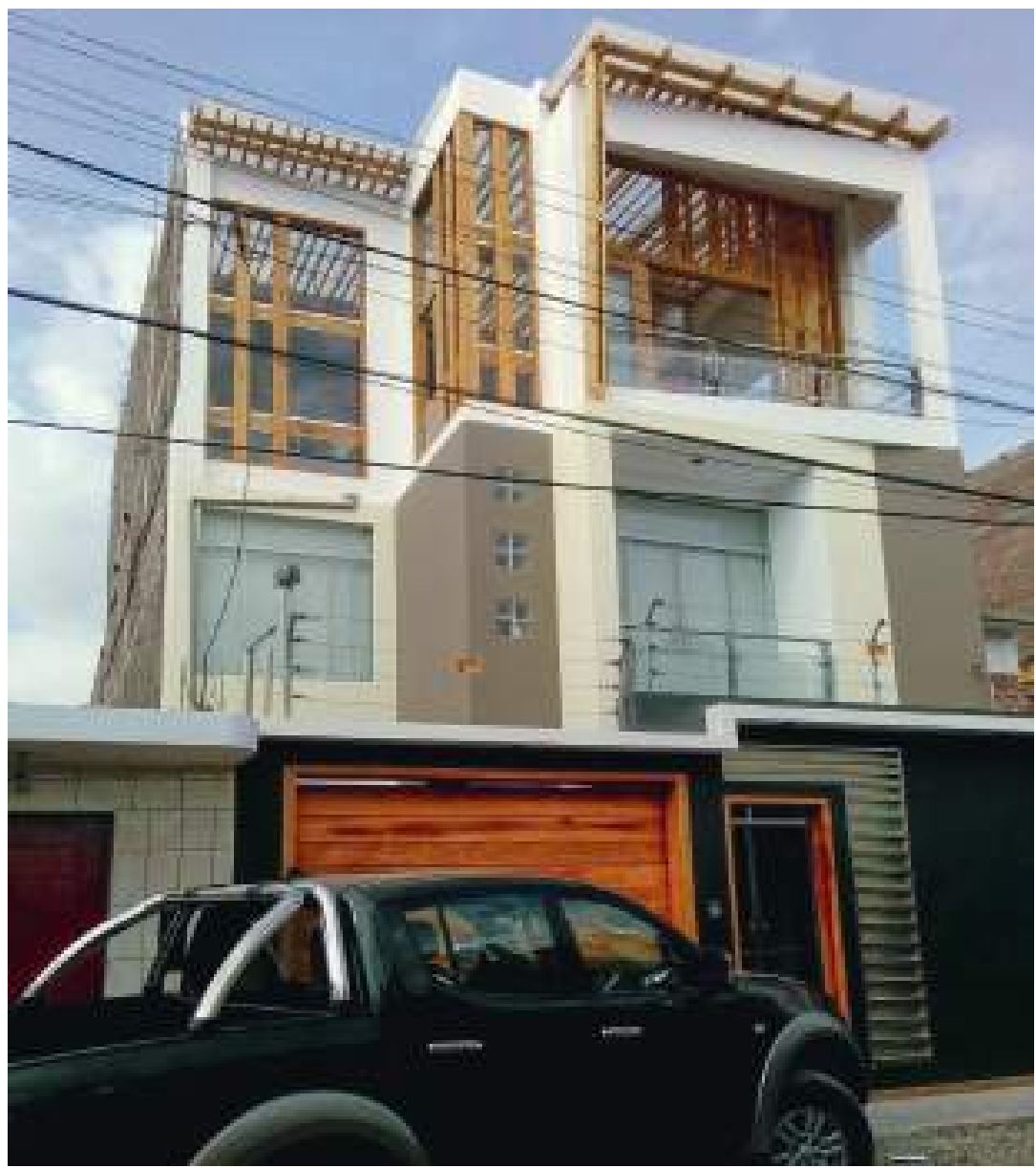

Figura 11. Caso 4 (Trujillo, 2010)

Fuente: fotografía del autor 


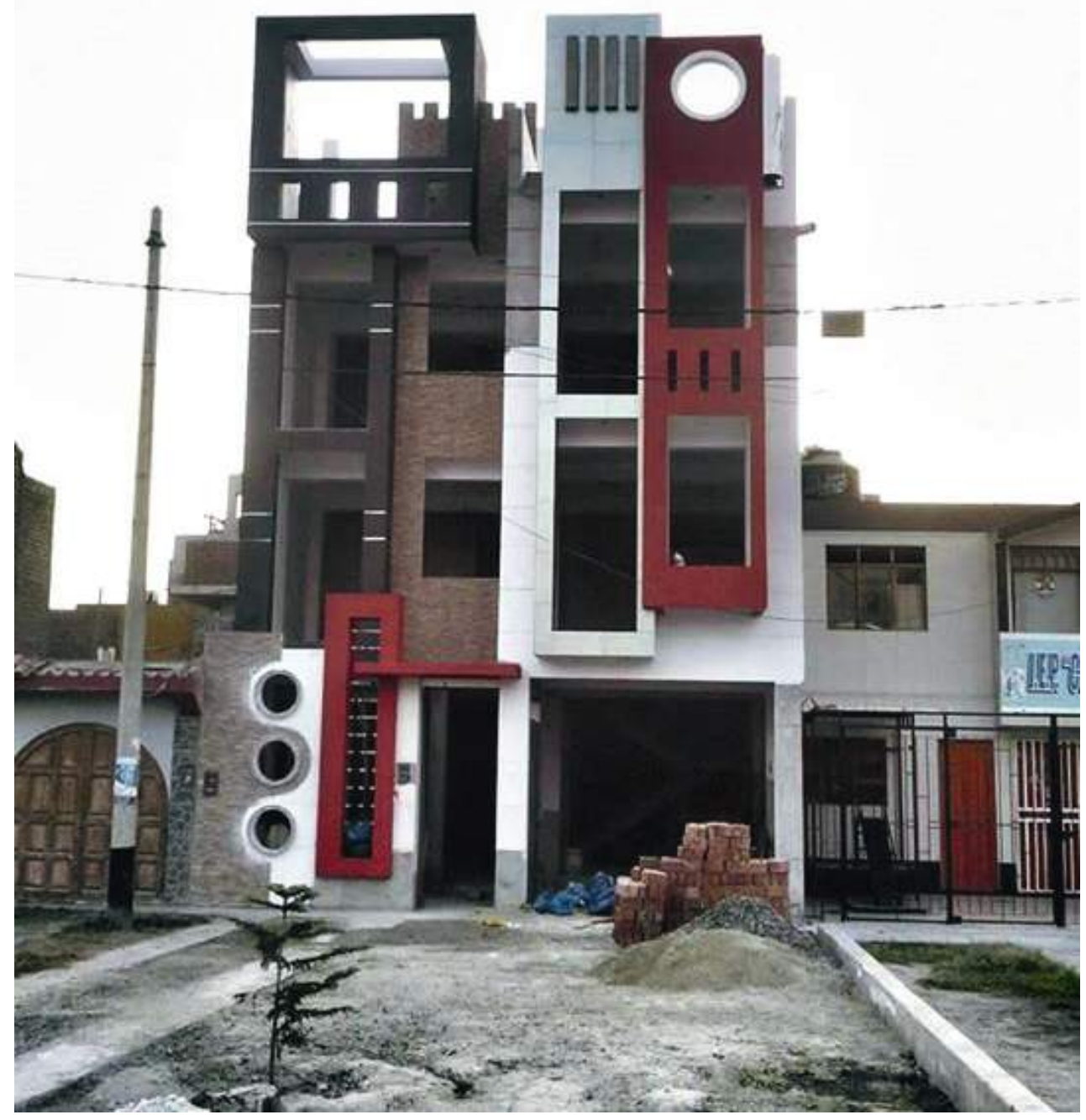

Figura 12. Caso 5 (Chimbote, 2011)

Fuente: archivo fotográfico de Richard Asto 


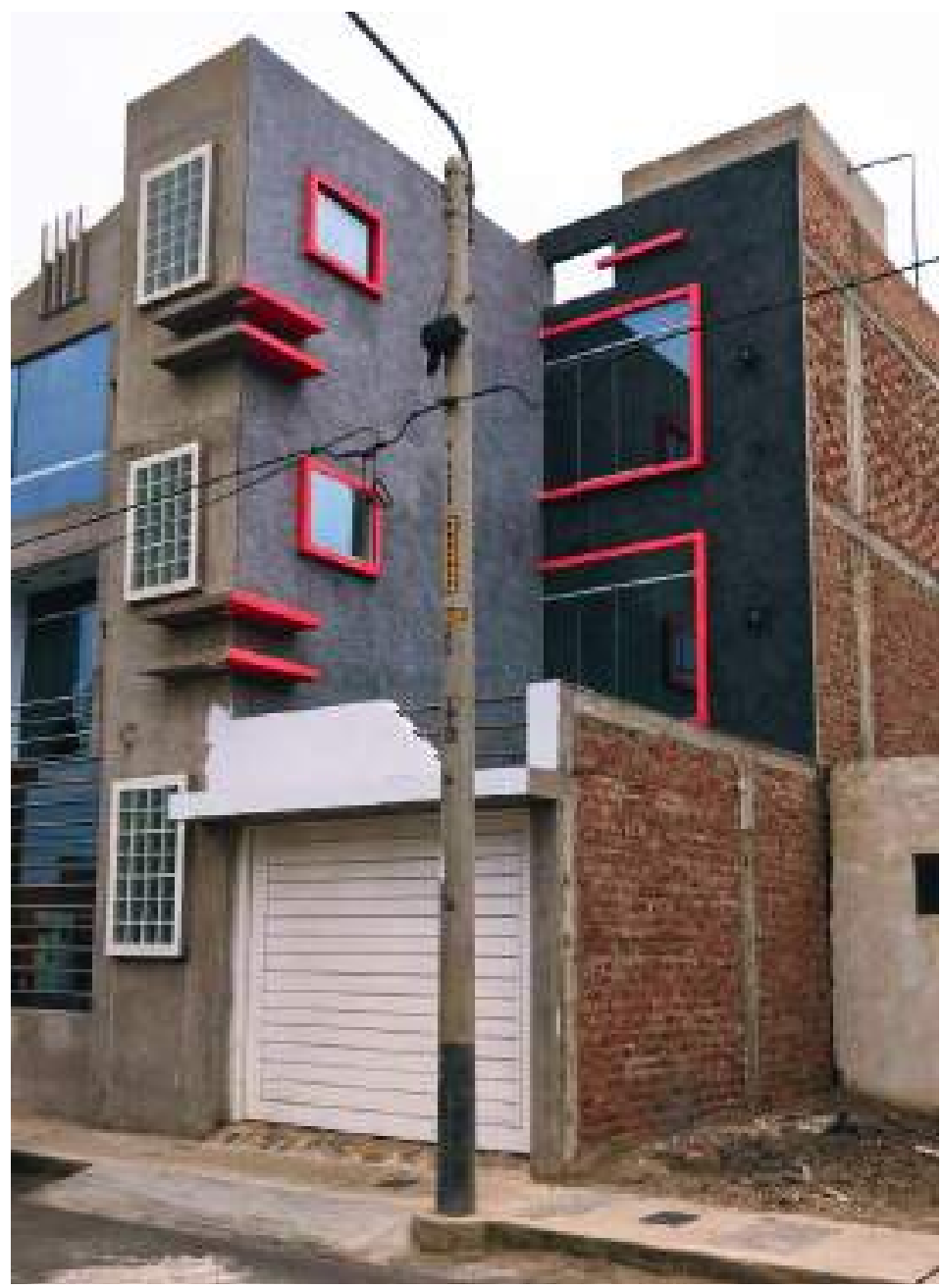

Figura 13. Caso 6 (Chiclayo, 2015)

Fuente: fotografía del autor 
En esta arquitectura peruana contemporánea, se evidencia la quiebra de códigos de criterio y pertinencia encontrados general e históricamente en varias manifestaciones racionales. Para José Beingolea, "la quiebra de los códigos es uno de los productos de este énfasis 'comunicativo", que genera en las ciudades una " "torre de babel' en la que conviven idiomas distintos que nadie entiende" (2011, p. 15). Esto resume la deformación del hecho proyectual.

También es común ver que el concepto y la metáfora sean entendidos desde la formación como soluciones magnas del proyecto arquitectónico, y que estas se mantengan como espectro reivindicatorio de estas obras. Es recurrente, entonces, que estos edificios "no hablen por sí mismos", sino que necesiten una justificación. Esta justificación queda solo en el espacio mental del proyectista, y, con suerte, al volcarse en los frentes; al interior de la obra, la conceptualización se torna innecesaria e irrelevante. El producto, en definitiva, es un edificio genérico y de reducido aporte proyectual-académico.

En resumen, lo "formal" de la arquitectura se convierte en un retoque de fachadas (con fines expositivos) cuando ya se ha salvado la proyección en planta, por lo que se hace casi de manera independiente y acomodando una a la otra para concluir el proyecto y aparentar un producto armónico. A pesar de dicha incongruencia, en sus respectivas zonas de acción y contextos próximos, estas obras son aceptadas en el imaginario del colectivo proyectual local, de los clientes y los usuarios. 

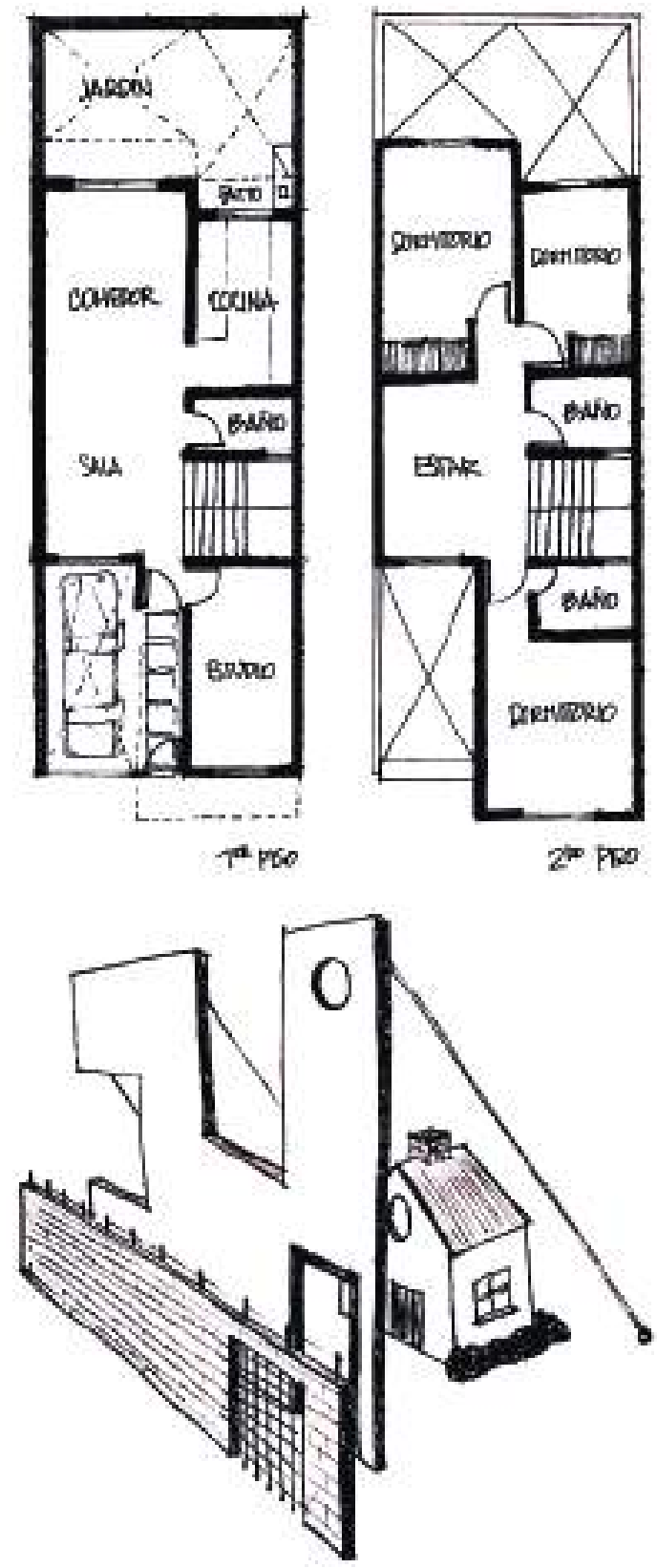

Figura 14. Esquematización del divorcio proyectual entre la distribución de ambientes y el tratamiento de las fachadas en viviendas unifamiliares

Fuente: Romero Alamo, 2013, p. 41 


\section{CONCLUSIONES}

La arquitectura residencial de la clase media de la costa norte del Perú, proyectada por arquitectos durante los primeros años del siglo XXI, tiene soluciones que se orientan a fines eminentemente comunicativos y exhibicionistas.

Esta arquitectura tiene su origen en la formación universitaria de las décadas de los noventa y en la primera del 2000, en un entorno académico de predominio posmoderno (que enfatiza la relación significado-significante y la presencia del concepto y la metáfora como criterios básicos de diseño). Esto tuvo su origen en la capital y su difusión posterior alcanzó gran acogida en el resto de zonas del país, sobre todo en la costa norte. A esto se le suma la influencia extranjera de la misma época: la presencia del star system internacional, la arquitectura como marketing e imagen y la existencia de grupos difusores de la corriente posmoderna, como los Five Architects.

Existe dentro de esta arquitectura un fin de ostentación del estatus adquirido, tanto en el cliente/usuario, para demostrar su superación socioeconómica,como en el arquitecto, para evidenciar un supuesto vanguardismo primermundista siguiendo "modelos de revistas" internacionales y nacionales.

La deformación proyectual se da a partir del énfasis en la forma y la tergiversación de la valía del edificio como ente integral. La quiebra de códigos y la generación de un edificio esquizofrénico (divorciado en sus partes constituyentes) hace que las edificaciones residenciales (proyectadas por arquitectos) terminen convirtiéndose en experimentos formales popularmente atractivos, de un estilo arquitectónico que poco a poco se torna dominante y de común aceptación entre clientes y usuarios. El público consumidor lo acepta porque tiene gustos e intereses afines a los proyectados por el arquitecto. El arquitecto es una proyección - en clave profesional- del usuario/cliente.

Esta arquitectura puede verse en varios contextos nacionales por razones similares a las expuestas para el norte peruano. Podría decirse que existe un hilo conductor común en la arquitectura contemporánea peruana: la frustración del producto académico combinada con una histórica tendencia cultural hacia lo barroco. 
Si bien existe una referencia importante en la arquitectura de remesas de países como Honduras, El Salvador y Guatemala, a raíz de la inversión económica de los migrantes centroamericanos en Estados Unidos, hay diferencias que son importantes de mencionar, pues las similitudes se centran solo en la expresión arquitectónica y en la intención demostrativa del usuario. No obstante, en dichos productos no se evidencia una "inversión proyectual", como en el caso de la costa norte del Perú, donde el profesional, a pesar de sus carencias teóricas, sí adquiere un papel determinante.

Esta arquitectura podría considerarse, en parte, para el Perú, equivalente a la arquitectura de Freddy Mamani en El Alto (Bolivia); es decir, como un ejercicio posmoderno, formal, de revestimientos y con interés por lo visual. Sin embargo, esta equivalencia se da solo en el producto final, pues el trabajo de Mamani se expone con una intención clara de revaloración cultural, mientras que, en el caso local, la expresión arquitectónica es acrítica y sin mayor intención revisionista o cuestionadora o siquiera teórica sustancial que supere el puro formalismo.

A diferencia de lo que especulan sus proyectistas, demuestra un intento por ser (o parecer) la arquitectura oficial, de revistas de starchitects o incluso de un ejercicio de taller pocas veces materializable. Esta arquitectura pretende ser oficial, pero los rezagos culturales expresados en sus frentes lo impiden. Por ello, su aceptación y difusión se mantiene en estratos bajos y oscuros de la profesión: la obra de estos arquitectos prácticamente es invisible para las altas esferas académicas, aunque su presencia en la "realidad" de las ciudades sea parte esencial de estas. Son edificios que se diluyen en una imagen urbana caótica y conflictiva, por lo que no suelen ser entendidos como "arquitectura", y sus autores, para la élite profesional, son entendidos como arquitectos anónimos. 


\section{REFERENCIAS}

Agencia Española de Cooperación. (2011). Arquitectura de remesas. México D. F: Autor

Beingolea, J. (2011). Aproximación al significante en la arquitectura de Chimbote. La Chimenea, (3), 14-15.

Dreifuss, C. (2013). Lo huachafo: una clave de lectura para la nueva arquitectura peruana. Arquitextos, (28), 93-98.

Eisenman Architects. (s. f.). House VI 1975. Recuperado de https:// eisenmanarchitects.com/House-VI-1975

Frampton, K. (2014). Historia crítica de la arquitectura moderna. Barcelona: Gustavo Gili. (Trabajo original publicado en 1980).

García Bryce, J. (1962). 150 años de arquitectura peruana. Lima: Sociedad de Arquitectos del Perú.

Graves M. Architecture \& Design. (s. f.). Hanselmann House. Recuperado de https://www.michaelgraves.com/projects/?category=interiordesign \&sector $=$ residential

Huaccha - Gestión académica. (3 de diciembre del 2012a). S. t. [imagen]. Recuperado de https://web.facebook.com/pg/huacchagestionacade mica/photos/?tab=album\&album_id=228765480590500

Huaccha - Gestión académica. (3 de diciembre del 2012b). S. t. [imagen]. Recuperado de https://www.facebook.com/huacchagestionacademica/ photos/a.229121887221526/231529606980754/?type=3\&theater

Iraheta, W. (s. f.). Arquitectura de remesas. Recuperado de http:// bibliotecadigital.aecid.es/bibliodig/es/catalogo_imagenes/grupo. cmd?path $=1006250$

Jencks, C. (1981). El lenguaje de la arquitectura posmoderna. Barcelona: Gustavo Gili.

Ludeña, W. (1989). De la u-topía a la a-patía. Lima:Arius. 
Massad, F. (2015). La viga en el ojo. Escritos a tiempo. Madrid: Ediciones Asimétricas.

Matos Mar,J. (2012) Perú. Estado desbordado y sociedad nacional emergente. Lima: Universidad Ricardo Palma.

Quijano, A. (2014). Cuestiones y horizontes. De la dependencia histórico-estructural a la colonialidad/descolonialidad del poder. Buenos Aires: Clacso.

Romero Alamo, I. (2013). (Ligero) Manual ilustrado para proyectar una vivienda del siglo XXI (según los principios de arquitecto contemporáneo promedio). Chimbote, Perú: Editorial La Chimenea.

Sveiven, M. (6 de febrero del 2012).AD Classics:Wall House 2 / John Hejduk, Thomas Muller/van Raimann Architekten \& Otonomo Architecten. Recuperado de https://www.archdaily.com/205541/ad-classics-wallhouse-2-john-hejduk

Uglyperuvianhouses. (19 de octubre del 2018). PatrimonioBerrinchudo [fotografia de Instagram].Recuperado de https://www.instagram.com/p/ BpIo4LRhXhV/?utm_source=ig_share_sheet\&igshid=1836yfgcyhmy4

Valencia, N. (25 de noviembre del 2017). Why Freddy Mamani is Leading A New Andean Architecture. Recuperado de https://www.archdaily. com/883951/why-freddy-mamani-is-leading-a-new-andeanarchitecture 